\title{
Morphological Phases in the Swarm of Bacillus licheniformis
}

\author{
By K. A. BISSET AND JILL STREET \\ Department of Bacteriology, University of Birmingham, Birmingham, B152TJ
}

(Received I January 1973)

\begin{abstract}
SUMMARY
The advancing edge of the active swarm of Bacillus licheniformis is surrounded with a fringe of non-flagellate, septate filaments. The mucoid portion of the colony is composed of short, flagellate bacilli. The two phases resemble Rough and Smooth forms occurring in the same colony.
\end{abstract}

\section{INTRODUCTION}

Bacillus licheniformis is a relatively small bacillus (about $\mathrm{I} \mu \mathrm{m}$ in diam., against about $2 \mu \mathrm{m}$ for B. cereus) it can swarm actively on moist agar plates, and also produces a growth, in culture on solid medium, that is well known but rarely described; the name derives from the central area of the colony that, under the low power of the microscope, resembles lichen, surrounded by bulging droplets of mucilaginous growth, and fringed with rhizoid filaments. This paper describes the morphology of the bacteria composing these different parts of the growth, which exist in phases that both parallel and differ from the morphological phases in the swarm of Proteus.

\section{METHODS}

One stock culture of Bacillus licheniformis NCTC I034I and ten strains isolated in this department from soil, dust and human pathological material were examined. They were grown on agar plates (BBL Trypticase Soy) that had been partially dried by being left, closed for $\mathrm{I} 8 \mathrm{~h}$ at $25{ }^{\circ} \mathrm{C}$. Cultures were incubated at $25^{\circ} \mathrm{C}$. Most observations and photomicrographs were made with the $\times$ I0 and $\times 40$ lenses of a Vickers phase-contrast microscope, upon surface growth on the uncovered plate, which was thus not constrained or interfered with (Bisset, I973); electron micrographs were made from simple suspensions, dried on the membrane, and gold-palladium shadowed. Sections were cut from material fixed with osmium tetroxide and embedded in Taab resin.

\section{RESULTS}

Swarming usually lasted only for a short time (Io to $24 \mathrm{~h}$ ). The growth was thin and flat, with a denticulate edge, superficially resembling the swarm of Proteus (Fig. I). When swarming ceased, the growth thickened considerably, over the area already occupied, but advanced only slowly (Fig. 2). Microscopically, the finger-like projections, at the edge of the swarm, could be seen by phase-contrast to consist of Medusa-head type growth, surrounded by a fringe of filaments (Fig. 3). These filaments extended rapidly, but were followed equally rapidly by the expanding edge of the colony, so that they remained short, but as the swarm began to progress more slowly, the relative length of the filaments increased (Fig. 4), and droplets of mucoid growth developed (Fig. 5). The development of this mucoid growth, from the previously existing filaments, could be seen at the edges of swarms from to to $24 \mathrm{~h}$ old. Nests of softer growth appeared among, and eventually overgrew the filaments in some, 

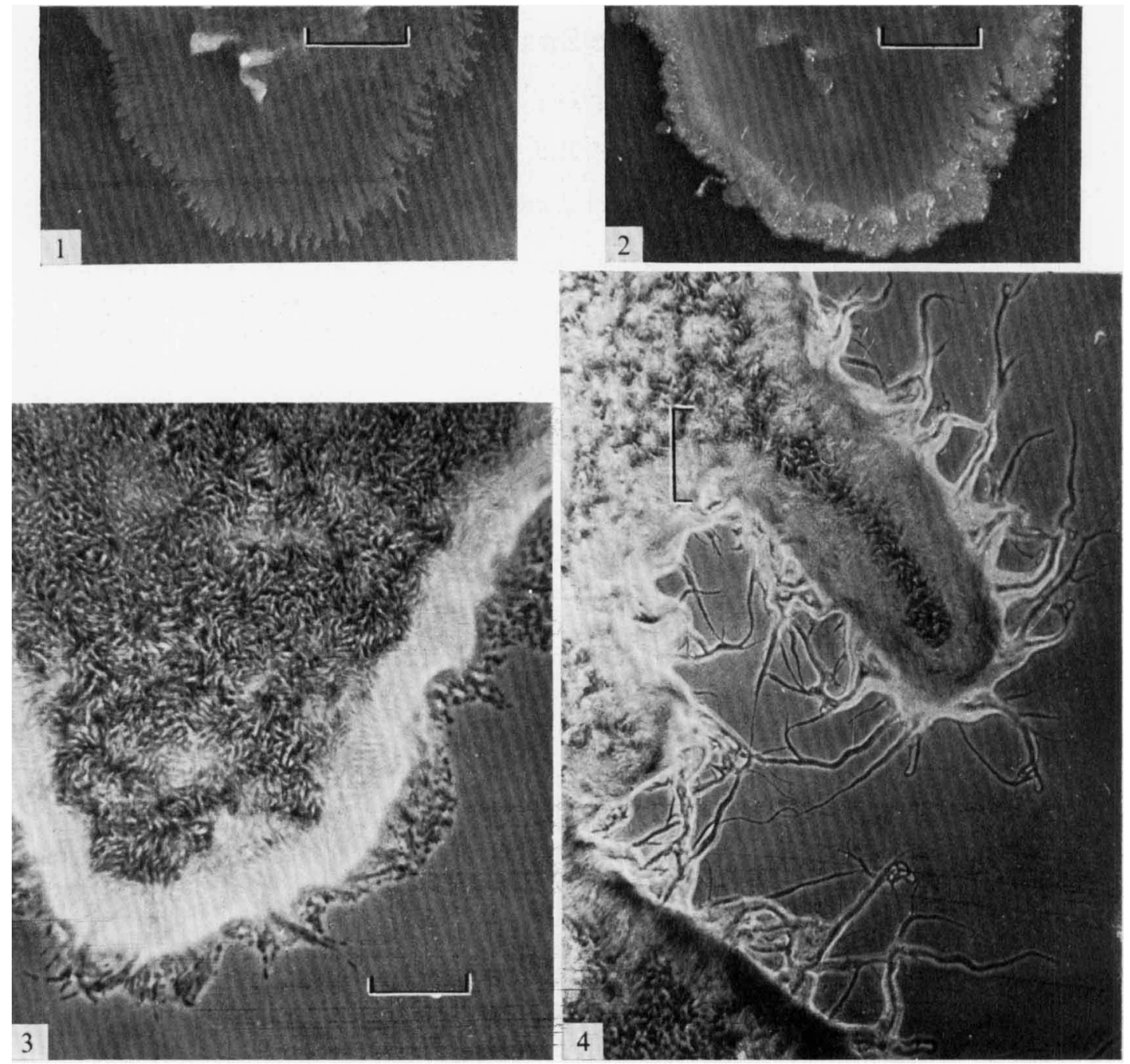

Fig. I. Portion of a young swarm $\left(20 \mathrm{~h}\right.$ at $\left.25^{\circ} \mathrm{C}\right)$ showing finger-like projections at the edge. The swarm has almost reached its fullest development. Reflected light in situ. The marker represents $4 \mathrm{~mm}$.

Fig. 2. The same growth as Fig. I at a later stage $\left(48 \mathrm{~h}\right.$ at $\left.25^{\circ} \mathrm{C}\right)$ showing the development of the typical 'licheniformis' appearance. (The scale and orientation may be checked by reference to the sigma-shaped protuberance.) Bright field in situ. The marker represents $4 \mathrm{~mm}$.

Fig. 3. One of the projections at the edge of the swarm showing a Medusa-head appearance with surrounding filaments. It is these filaments that advance rapidly in the spread of the swarm. Phase contrast in situ. The marker represents $25 \mu \mathrm{m}$.

Fig. 4. A similar projection to Fig. 3 but slightly older (about $30 \mathrm{~h}$ ). The filaments are considerably longer by comparison; the swarm is still advancing but more slowly. Phase contrast in situ. The marker represents $50 \mu \mathrm{m}$. 


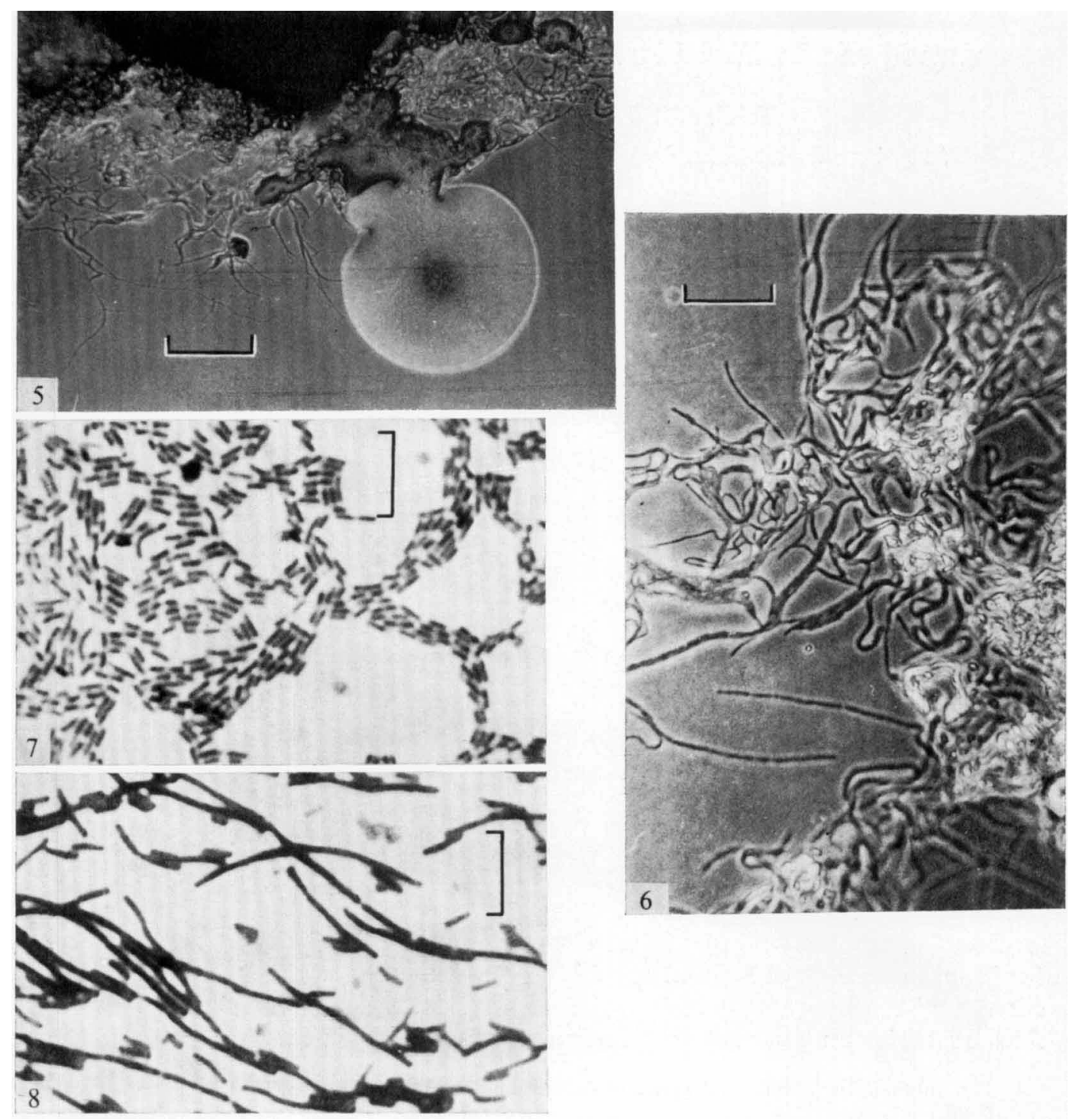

Fig. 5. The same stage of development as Fig. 4; appearance of a droplet of mucoid growth at the edge of the colony. Phase contrast in situ. The marker represents $90 \mu \mathrm{m}$.

Fig. 6. Similar stage to Fig. 5 showing the development of mucoid growth among the filaments at the edge of the colony. Phase contrast in situ. The marker represents $25 \mu \mathrm{m}$.

Fig. 7. Gram-stained film of short bacilli from mucoid growth. The marker represents $10 \mu \mathrm{m}$.

Fig. 8. Gram-stained film of filamentous bacilli. The marker represents $10 \mu \mathrm{m}$.

but not all areas (Fig. 6). The morphology of the constituent bacteria was entirely distinct, by ordinary staining methods (Fig. 7,8), by Tannic acid-violet (Fig. 9 to II) and by electron microscopy (Fig. I2, I3). The filaments were often $50 \mu \mathrm{m}$ in length or more and composed of long, sepate bacilli, with few flagella or none. The soft growth was composed of bacilli from 3 to $5 \mu \mathrm{m}$ in length, non-septate and bearing about 7 to Io flagella. They were 

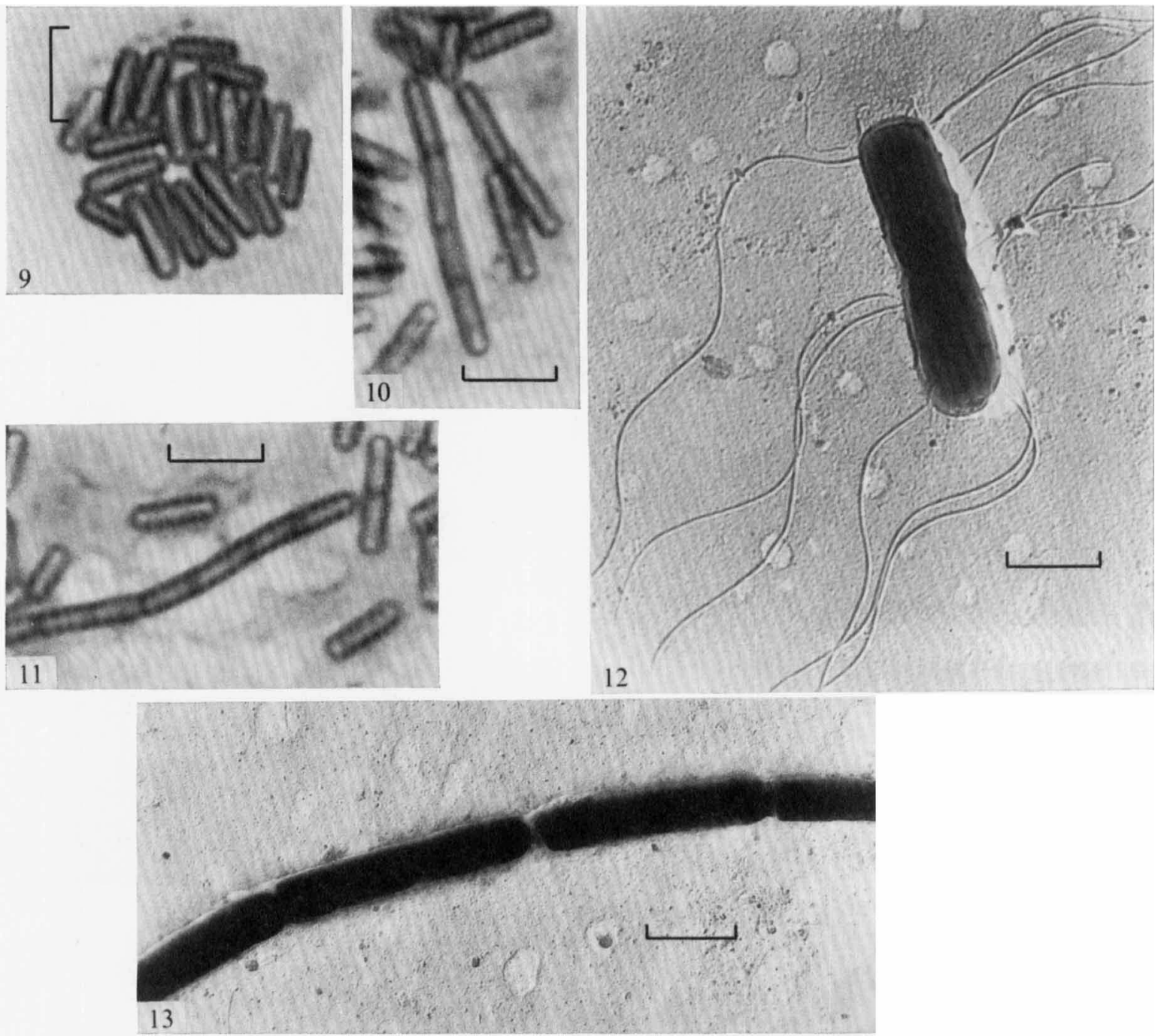

Fig. 9. Wall stain (Tannic acid-violet) of short bacilli from mucoid growth. The marker represents $6 \mu \mathrm{m}$.

Fig. IO, I I. Wall stain (Tannic acid-violet) of filamentous bacilli showing numerous cross-walls. The marker represents $6 \mu \mathrm{m}$.

Fig. I2. Short bacillus from mucoid growth showing flagella. Electron micrograph gold-palladium shadowed. The marker represents I $\mu \mathrm{m}$.

Fig. I3. Portion of filament showing comparative absence of flagella (the unattached fragments of flagella may or may not belong to this organism). Electron micrograph gold-palladium shadowed. The marker represents $\mathrm{I} \cdot 5 \mu \mathrm{m}$.

the same (about I $\mu \mathrm{m}$ ) in diam. Spores were produced in moderate amounts in the short bacilli, and were rare in the filaments. Attempts were made by means of sectioning techniques to demonstrate any differences that might exist between the cell envelopes of these two types, but none could be perceived. 


\section{DISCUSSION}

The morphological types described correspond precisely to the Rough and Smooth phase morphologies, as described by Bisset (1938, I970). In Bacillus species, it is often the septate, filamentous Rough form which gives rise to a unicellular, short Smooth variant (unlike the common $\mathbf{S} \rightarrow \mathbf{R}$ variation of Gram-negative bacteria). However, in the case of Bacillus licheniformis, the relationship is not a variation but a change of growth phase that occurs regularly in the course of growth of a single, pure culture, and is repeated on subculture. The true parallel is with the phases of the swarm of Proteus, but the disposition of the phases of $B$. licheniformis, with relation to the swarming phenomenon in that species, is remarkable, in that the elongated forms which spearhead the swarm are non-motile, by contrast with the short, motile forms in the non-swarming phase. This, however, is less of a contrast to the condition in Proteus than might be believed; for it has been shown (Bisset, I973), by the same techniques, that although the elongated bacteria which form the leading edge of the swarm of Proteus are flagellate and motile, the growth of the swarm is an important element in its advance, as also in $B$. licheniformis, here described.

\section{REFERENCES}

Bisset, K. A. (1938). The structure of rough and smooth colonies. Journal of Pathology and Bacteriology 47, 223-229.

Bisset, K. A. (1970). The Cytology and Life-History of Bacteria, 3rd edn, pp. 24 and I22. Edinburgh: Livingstone.

Bisset, K. A. (1973). The motion of the swarm in Proteus mirabilis. Journal of Medical Microbiology 6, 33-35. 